\title{
Identification of Rare Recurrent Copy Number Variants in High-Risk Autism Families and Their Prevalence in a Large ASD Population
}

\author{
Nori Matsunami ${ }^{19}$, Dexter Hadley ${ }^{29}$, Charles H. Hensel ${ }^{39}$, G. Bryce Christensen ${ }^{4}$, Cecilia Kim ${ }^{2}$, \\ Edward Frackelton ${ }^{2}$, Kelly Thomas ${ }^{2}$, Renata Pellegrino da Silva ${ }^{2}$, Jeff Stevens', Lisa Baird', \\ Brith Otterud ${ }^{1}$, Karen Ho $^{3}$, Tena Varvil ${ }^{1}$, Tami Leppert ${ }^{1}$, Christophe G. Lambert ${ }^{4}$, Mark Leppert ${ }^{1}$, \\ Hakon Hakonarson ${ }^{2,5 *}$
}

1 Department of Human Genetics, University of Utah, Salt Lake City, Utah, United States of America, 2 Center for Applied Genomics, The Children's Hospital of Philadelphia, Philadelphia, Pennsylvania, United States of America, 3 Lineagen, Inc., Salt Lake City, Utah, United States of America, 4 Golden Helix, Inc., Bozeman, Montana, United States of America, $\mathbf{5}$ Department of Pediatrics, University of Pennsylvania School of Medicine, Philadelphia, Pennsylvania, United States of America

\begin{abstract}
Structural variation is thought to play a major etiological role in the development of autism spectrum disorders (ASDs), and numerous studies documenting the relevance of copy number variants (CNVs) in ASD have been published since 2006. To determine if large ASD families harbor high-impact CNVs that may have broader impact in the general ASD population, we used the Affymetrix genome-wide human SNP array 6.0 to identify 153 putative autism-specific CNVs present in 55 individuals with ASD from 9 multiplex ASD pedigrees. To evaluate the actual prevalence of these CNVs as well as 185 CNVs reportedly associated with ASD from published studies many of which are insufficiently powered, we designed a custom Illumina array and used it to interrogate these CNVs in 3,000 ASD cases and 6,000 controls. Additional single nucleotide variants (SNVs) on the array identified 25 CNVs that we did not detect in our family studies at the standard SNP array resolution. After molecular validation, our results demonstrated that 15 CNVs identified in high-risk ASD families also were found in two or more ASD cases with odds ratios greater than 2.0, strengthening their support as ASD risk variants. In addition, of the 25 CNVs identified using SNV probes on our custom array, 9 also had odds ratios greater than 2.0, suggesting that these CNVs also are ASD risk variants. Eighteen of the validated CNVs have not been reported previously in individuals with ASD and three have only been observed once. Finally, we confirmed the association of 31 of 185 published ASD-associated CNVs in our dataset with odds ratios greater than 2.0, suggesting they may be of clinical relevance in the evaluation of children with ASDs. Taken together, these data provide strong support for the existence and application of high-impact CNVs in the clinical genetic evaluation of children with ASD.
\end{abstract}

Citation: Matsunami N, Hadley D, Hensel CH, Christensen GB, Kim C, et al. (2013) Identification of Rare Recurrent Copy Number Variants in High-Risk Autism Families and Their Prevalence in a Large ASD Population. PLoS ONE 8(1): e52239. doi:10.1371/journal.pone.0052239

Editor: Michael Edward Zwick, Emory University School Of Medicine, United States of America

Received September 6, 2012; Accepted November 9, 2012; Published January 14, 2013

Copyright: (c) 2013 Matsunami et al. This is an open-access article distributed under the terms of the Creative Commons Attribution License, which permits unrestricted use, distribution, and reproduction in any medium, provided the original author and source are credited.

Funding: All Utah subjects were ascertained and DNA collected with support from R01 MH 06359 from the National Institute of Mental Health and U19HD035476 from the National Institute of Child Health and Human Development. DNA was processed with support from GCRC M01-RR025764 from the National Center for Research Resources. The Autism Genetic Resource Exchange is a program of Autism Speaks and is supported, in part, by grant 1 U24MH081810 from the National Institute of Mental Health to Clara M. Lajonchere (PI). Dr. Hakonaron is additionally supported by the Margaret Q. Landenberger Foundation. Additional funding for this study was provided by Lineagen, Inc. Scientific input into study design, data analysis, and preparation of the manuscript were provided by two authors who are Lineagen employees $(\mathrm{CHH}, \mathrm{KH})$. The remaining funders had no role in study design, data collection and analysis, decision to publish, or preparation of the manuscript.

Competing Interests: Bryce Christensen and Christophe Lambert are paid employees of Golden Helix Inc., which derives commercial revenue from the SNP \& Variation Suite software used for data analysis for this publication. Nori Matsunami, Charles Hensel and Mark Leppert have stock options in Lineagen, Inc. These affiliations do not alter the authors' adherence to all the PLOS ONE policies on sharing data and materials.

* E-mail: hakonarson@email.chop.edu

9 These authors contributed equally to this work.

\section{Introduction}

Twin studies [1-3], (reviewed in [4]), family studies [5-7], and reports of chromosomal aberrations in individuals with ASD (reviewed in [8]) all have strongly suggested a role for genes in the development of ASD. Although the magnitude of the genetic effect observed in ASD varies from study to study, it is clear that genetics plays a significant role.

While a number of genes associated with ASD susceptibility have been observed in multiple studies, variants in a single gene cannot explain more than a small percentage of cases. Indeed, recent estimates suggest that there may be nearly 400 genes or chromosomal regions involved in ASD predisposition [9-12].

In the past few years, a number of studies have identified both $d e$ novo and inherited structural variants, including CNVs, that are associated with ASD [13-23]. De novo CNVs may explain at least some of the "missing heritability" of ASD as understood to date. While it is clear that CNVs play an important role in susceptibility to ASD, it is also clear that the genetic penetrance of many of these CNVs is less than $100 \%$. Although many of the duplications or 
deletions observed in children with ASD occur as de novo variants, duplications, for example on chromosome 16p11.2, often are inherited from an asymptomatic parent. Moreover, both deletions and duplications encompassing a portion of chromosome 16p11.2 have been associated with ASD [21,24-26] and 16p11.2 gains have been associated with ADHD and schizophrenia [24,27-29], indicating that the same genomic region can be involved in multiple developmental conditions. In addition, deletions on chromosome 7q11.23 are known to cause Williams syndrome and duplications of this same region have been observed and are thought to be causal in individuals with ASD [9,11]. While individuals with Williams syndrome tend to be outgoing and social, individuals with ASD are socially withdrawn, suggesting that deletions and duplications in this region result in individuals on opposite sides of the behavioral spectrum.

Although numerous studies regarding the role of CNVs in ASD have been published in the research literature, the findings of these studies have not been fully utilized for clinical evaluation of children with ASD. This is likely due to the rarity of individual variants, the lack of probe coverage on clinical microarrays that permits detection of smaller variants, and the difficulty in understanding the relevant biology of some variants even when they are significantly associated with ASD. Despite this, published clinical guidelines suggest that microarray-based testing should be the first step in the genetic analysis of children with syndromic and non-syndromic ASD as well as other conditions of childhood development [30], and there is a wealth of information demonstrating its utility in large samples of children who have undergone such testing $[25,31]$.

In this work we describe our efforts to discover high-impact CNVs in high-risk ASD families in Utah and to assess their potential role in unrelated ASD cases. We interrogated these CNVs, as well as CNVs from multiple published sources [18,32] in a large sample set of ASD cases and controls, to determine more precisely their potential disease relevance. To evaluate carefully these CNVs, we designed a custom Illumina iSelect array containing probes within and flanking $\mathrm{CNV}$ regions of interest. We used this custom array to obtain high-quality CNV results on 2,175 children with clinically diagnosed ASD and 5,801 children with normal development following removal of samples that did not meet our stringent quality control parameters. The results of this study identify multiple rare recurrent GNVs from high-risk ASD families that also confer risk in unrelated ASD cases and delineate the prevalence and impact of GNVs reported in the literature in a large case control study of ASDs.

\section{Results}

\section{CNV discovery in Utah high risk autism pedigrees}

Using CNAM (GoldenHelix Inc.) on Affymetrix Genome-Wide Human SNP array 6.0 data, we identified a total of 153 CNVs in subjects with autism in Utah families that were not found in any of our CEPH/UGRP control samples. This set included 131 novel CNVs and 22 CNVs present in the Autism Chromosomal Rearrangement Database [15]. Thirty-two autism-specific CNVs were detected in multiple (2 or more) autism subjects, and 121 CNVs were detected in only one person among the 55 autism subjects assayed. Of these $153 \mathrm{CNVs}, 112$ were copy number losses (deletions) and 41 were copy number gains (duplications). The average size of the CNVs from high-risk families was $91 \mathrm{~kb}$. The genomic locations of these CNVs are shown in Table S2 in File S1.
Table 1. Case and control samples used in this study.

\begin{tabular}{llllll}
\hline & & & & \\
\hline & case & & & control \\
\cline { 2 - 3 } \cline { 5 - 6 } & male & female & & male & female \\
\hline AGRE/AGP & 1,517 & 626 & 0 & 0 \\
CHOP & 633 & 224 & 3,992 & 2,008 \\
sub-total & 2,150 & 850 & & 3,992 & 2,008 \\
grand-total & 3,000 & & 6,000 & \\
\hline
\end{tabular}

doi:10.1371/journal.pone.0052239.t001

\section{CNV regions on the custom array}

To better understand the frequency of the GNVs identified in Utah ASD families in a broader ASD population, we created a custom Illumina iSelect array containing probes covering all 153 of the Utah CNVs described in Table $\mathrm{S} 2$ in File S1. CNV coordinates, copy number status, and probe content for each CNV are included. In addition, since the ultimate goal of this work is to understand the frequency and relevance of rare recurrent GNVs in the etiology of ASD, we included probes for 185 autism-associated CNVs identified in the literature [14-16,18,21,32,33] (Table S3 in File S1). The probe coverage for each literature CNV also is shown in Table S3 File S1. In total, 7134 probes, all selected from the Illumina $2.5 \mathrm{M}$ array, were used for this study. As part of a separate study we also included 2,799 SNVs detected by nextgeneration sequencing of genes in regions of haplotype sharing among our high-risk ASD families and in published ASD candidate genes in these same individuals. Intensity data for these SNVs were used to identify additional CNVs that were not observed in our Utah high-risk ASD families (Table S4 in File S1). Following standard data QC steps (see supplemental results) this array was used to characterize which of these $363 \mathrm{CNVs}$ were present in DNA from 2,175 children with autism and 5,801 age, gender, and ethnicity matched controls (Table 1). These 7976 samples were available for analysis following our strict quality control measures (File S2).

\section{Analysis of CNVs on the iSelect array}

The workflow for CNV analysis of the custom array data is shown in Figure 1. Following quality control analysis, including removal of samples that did not meet laboratory sample quality control measures, samples with excessive CNV calls, samples of uncertain ethnicity, and related samples, our final dataset included 1544 unrelated cases and 5762 unrelated controls. Because of the inherent noisiness of CNV analysis, we used two independent GNV calling algorithms, PennCNV [34] and CNAM (Golden Helix, Inc.), to increase our ability to detect CNVs. We identified 6,086 CNVs in cases and 14,387 CNVs in controls using PennCNV and 3,226 CNVs in cases and 8,234 CNVs in controls using CNAM. 1,537 CNVs from the 2175 cases including those from multiplex families (average $0.70 \mathrm{CNVs}$ per individual) and 3,845 CNVs from the 5801 controls including related controls (average of $0.66 \mathrm{CNVs}$ per individual) were called by both algorithms used for CNV detection.

All CNV regions harboring CNVs shared among subjects were defined from PennCNV calls, GNAM calls and the PennCNV/ CNAM intersecting calls and their significance of association was calculated across the genome (Figure 2). Of the $153 \mathrm{CNVs}$ discovered in high-risk ASD families, 139 of them were seen in replication samples evaluated with the custom Illumina iSelect array. Seven of the GNVs not seen in this larger population study 
All Samples: 3000 cases, 6000 controls

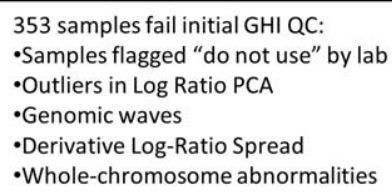

Samples with sufficient quality for segmentation: 2784 cases, 5863 controls

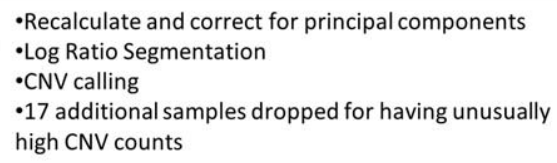

Samples with CNV calls for analysis: 2780 cases, 5850 controls

959 samples failed to meet "high-quality" thresholds in CHOP analysis

Samples passing QC in independent GHI and CHOP analyses: 2393 cases, 5278 controls

565 samples removed because they are nonCaucasian based on analysis of SNP principal components.

Final set of Caucasian samples: 1885 cases, 5221 controls.

$$
\begin{aligned}
& 290 \text { case samples and } 580 \text { control samples with } \\
& \text { significant waviness were added back to evaluate } \\
& \text { CNVs called in higher quality samples. These } \\
& \text { samples had signal/noise ratios that made them } \\
& \text { interpretable for the specific CNVs being evaluated. }
\end{aligned}
$$

Evaluated set of Caucasian samples: 2175 cases, 5801 controls.

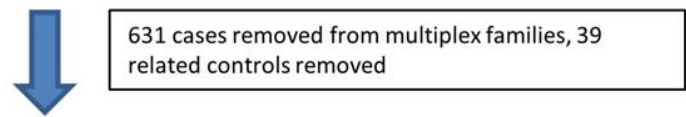

Final set of unrelated Caucasian samples: 1544 cases, 5762 controls.

Figure 1. Workflow for CNV analysis for samples analyzed on the custom array. The same process was used for both CNAM and PennCNV analyses. All samples used for CNV analysis in this study had to meet the quality control measures described. Only unrelated cases and controls were used for the final statistical analysis.

doi:10.1371/journal.pone.0052239.g001

had poor probe coverage on the array either due to their small size or their genomic content, while the remainder that were not detected may represent false positive CNVs from our initial discovery work or may be rare $\mathrm{CNV}$ s that are private to the families or individuals in which they were identified.

\section{Molecular validation of CNV calls}

We used TaqMan copy number assays to confirm the presence of CNVs in our population. A summary of the 195 TaqMan assays used is shown in Table $\mathrm{S} 1$ in File S1. Since our goal for this study was to understand the frequencies of these CNVs in a large case/ control population, we chose to validate any GNVs that were likely to have clinical relevance. Our criteria for selection were as follows: 1) any CNV with an odds ratio $>=2.0$; 2) any rare CNV seen in at least two cases. We chose these criteria for selecting GNVs to validate because our goal was to translate research GNV findings into potentially clinically useful markers. Since clinical testing of individuals with ASD is only performed on people who are symptomatic, GNVs with odds ratios $<1.0$ (GNVs that indicate lower than average risk of $\mathrm{ASD}$ ) were not chosen for validation. Likewise, since CNVs with odds ratios $>=1$ but $<=2$ do are not of great diagnostic interest, we chose to validate only CNVs with odds ratios $>=2.0$. By using these criteria, we included rare recurrent CNVs that may be etiologically important despite the lack of statistical significance in cases versus controls. For previously published CNVs we considered our custom Illumina iSelect array as an independent test of their validity. We assumed therefore that these CNVs did not require additional testing. Since some of the CNVs from The Children's Hospital of Philadelphia (CHOP) were not included in previous publications $[18,32]$, we selected all CHOP CNVs for molecular validation. For CNVs that met our selection criteria we assayed a maximum of six case samples that contained the GNV, giving priority to those samples called both by PennCNV and CNAM. Results of these TaqMan experiments are summarized in Table 2. Interestingly, many of the most common CNVs detected by the array were not validated by the TaqMan assays. For example, when we tested samples from a statistically significant GNV duplication on chromosome 7q36.1 that was detected only by PennCNV and not by CNAM, all samples tested were shown to have two copies rather than the anticipated three copies, suggesting that in this sample set at least some of the CNV duplications observed are not true positives. Conversely all but one of the CNVs observed on chromosome 15, whether in the Prader-Willi/Angelman syndrome region or located more distally on chromosome 15 , were confirmed by TaqMan assays. Results of these validation 


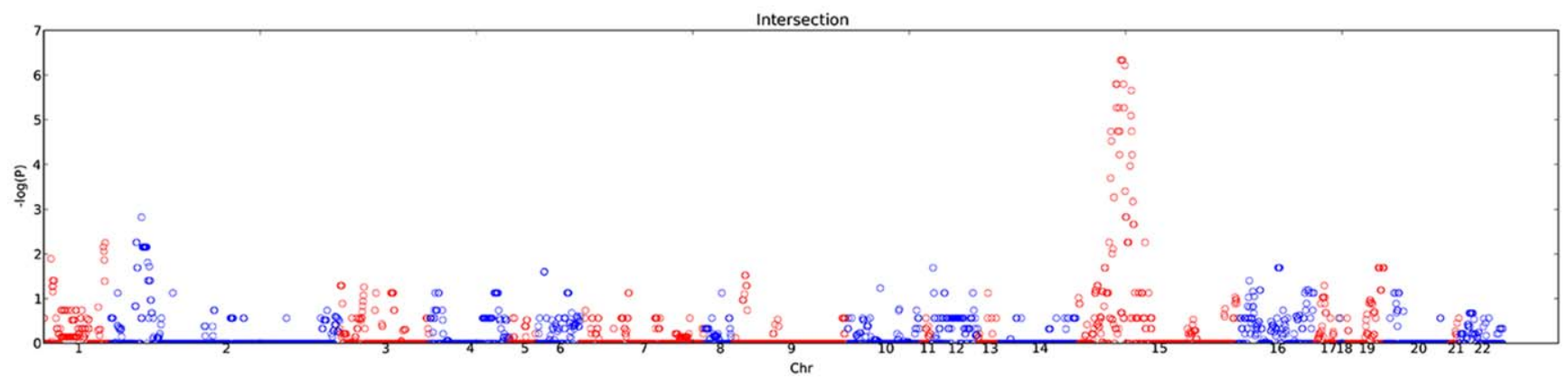

Figure 2. Manhattan plot of CNVs called both by PennCNV and CNAM. Association statistics across all regions covered on the Illumina custom array are shown. Since the array used was not a genome-wide array, the width of each chromosome on the plot is not proportional to the chromosome length. Adjacent chromosomes are displayed in alternating red and blue colors to aid in distinguishing them. doi:10.1371/journal.pone.0052239.g002

experiments demonstrated that CNVs called both by PennCNV and CNAM were much more likely to be confirmed $(97 \%$ of tested samples) than CNVs called by either PennCiNV alone (24\%) or CNAM alone (30\%). This observation demonstrates the care that must be taken during the CNV discovery process to insure that only valid calls are selected for further analysis.

False negative results also are possible with our microarray studies. However, the controls that we used for TaqMan assays were selected from our control sample set because they lacked CNV calls for any of the regions being evaluated. In none of these samples did the TaqMan results indicate the presence of any of the CNVs being validated, so no false negative results were detected. These data suggest that false negative results are not a common problem in this study.

\section{CNVs from high-risk Utah families}

One hundred thirty-nine of the $153 \mathrm{CNVs}$ identified in highrisk ASD families were observed in case and/or control samples in this large dataset. Of these, 33 were present in two or more cases and had odds ratios greater than 2 and thus were selected for molecular confirmation. Following TaqMan validation, fifteen of the thirty-three CNVs were validated (Table 3). Of the 15 validated CNVs identified in high-risk families, 4 were shown to be inherited CNVs while three were de novo CNVs in the discovery families. The remainder were of undetermined origin, in most cases due to lack of information for one or both parents. A CNV that was validated in some samples but not in others, for example if a CNV was validated in all calls made by both PennCNV and CNAM but was not validated in all calls made only by one program, was considered to have passed validation if the validated

Table 2. Confirmation of CNV calls by quantitative PCR.

\begin{tabular}{lllll}
\hline $\begin{array}{l}\text { TaqMan CNV } \\
\text { Validation } \\
\text { Status }\end{array}$ & $\begin{array}{l}\text { Utah Family } \\
\text { CNVs }\end{array}$ & $\begin{array}{l}\text { Utah Sequence } \\
\text { SNP CNVs }\end{array}$ & $\begin{array}{l}\text { Literature } \\
\text { CNVs }\end{array}$ & Total \\
\hline PASS & $\begin{array}{l}\text { 24 (2 overlap } \\
\text { with Lit. CNV) }\end{array}$ & 15 & 25 & 64 \\
FAlL & 9 & 9 & 5 & 23 \\
NoCall & 0 & 1 & 0 & 1 \\
\hline A & 0 & & & \\
\hline
\end{tabular}

A summary of the PCR validation result is shown. Sequence SNP CNVs were discovered in this work using SNVs present on this array for sequence variant confirmation in the same cohort.

doi:10.1371/journal.pone.0052239.t002 samples yielded an odds ratio greater than 2.0 with at least two cases confirmed by validation.

Notable among these CNVs is a deletion observed near the 5'-

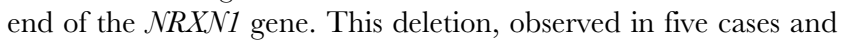
only in one control, includes at least a portion of the $\mathcal{N} R X \mathcal{N} 1$-alpha promoter, and extends into the first exon of $\mathcal{N} L R X N 1-\alpha$, as shown in the UCSG Genome Browser view [35] (Figure 3). GNVs impacting $\mathcal{N R X N 1}$ in ASD as well as other neurological conditions have been published by others [15,32,36-40], so the observation

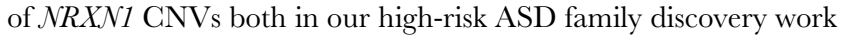
and in the large case/control replication study demonstrates our ability to detect biologically relevant CNVs that may also have clinical utility.

Other CNVs of interest included portions of the LINGO2 and STXBP5 genes. Single nucleotide variants in the LINGO2 gene have been associated with essential tremor and with Parkinson's disease, suggesting that the LINGO2 protein may have a neurological function [41]. However, CNVs in this gene have not previously been identified in individuals with ASD. We also observed deletions involving a portion of the STXBP5 gene, an interesting finding based on the potential role of STXBP5 in neurotransmitter release $[42,43]$.

\section{CNVs Identified by SNV Probes}

Twenty-five additional CNVs shown in Table 3 were discovered using SNVs identified in our high-risk ASD families. The SNVs that detected these twenty-five CNVs (Table S4, File S1) were identified by exon capture and DNA sequencing in regions of haplotype sharing and in published ASD candidate genes in our high-risk ASD families, and were selected for further study because they might alter the function of the proteins in which they were found (unpublished observations). The 9 validated CNVs derived from SNV intensity data are shown in Table 3 (CNVs not detected in discovery cohort). One of these CNVs, a chromosome $15 q$ duplication, encompasses three duplication CNVs in Table 4. These three GNVs are thought to be contiguous since TaqMan data confirmed the same samples to be positive for each of them.

Interestingly, duplications involving the GABA receptor gene cluster, as well as many other genes, on chromosome 15 q12 were observed in 11 unrelated cases in our study and only in a single control, shown in the UCSC Genome Browser view [35](Figure 4). Contrary to our findings, a recent search for CNVs in GABA pathway genes [44] did not find an enrichment of duplications in this region. Rather, both deletions and duplications were observed at similar frequencies in cases and controls. 


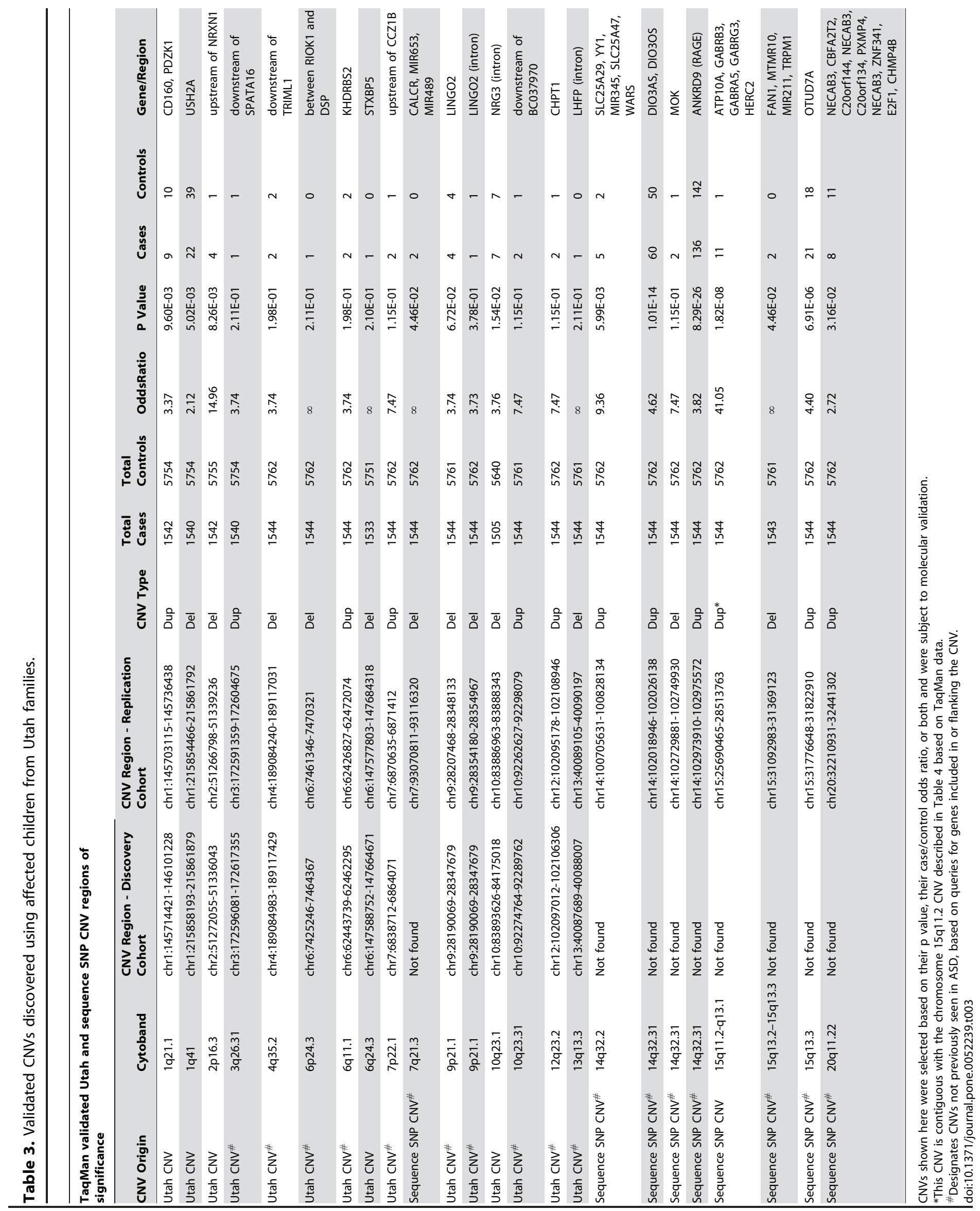




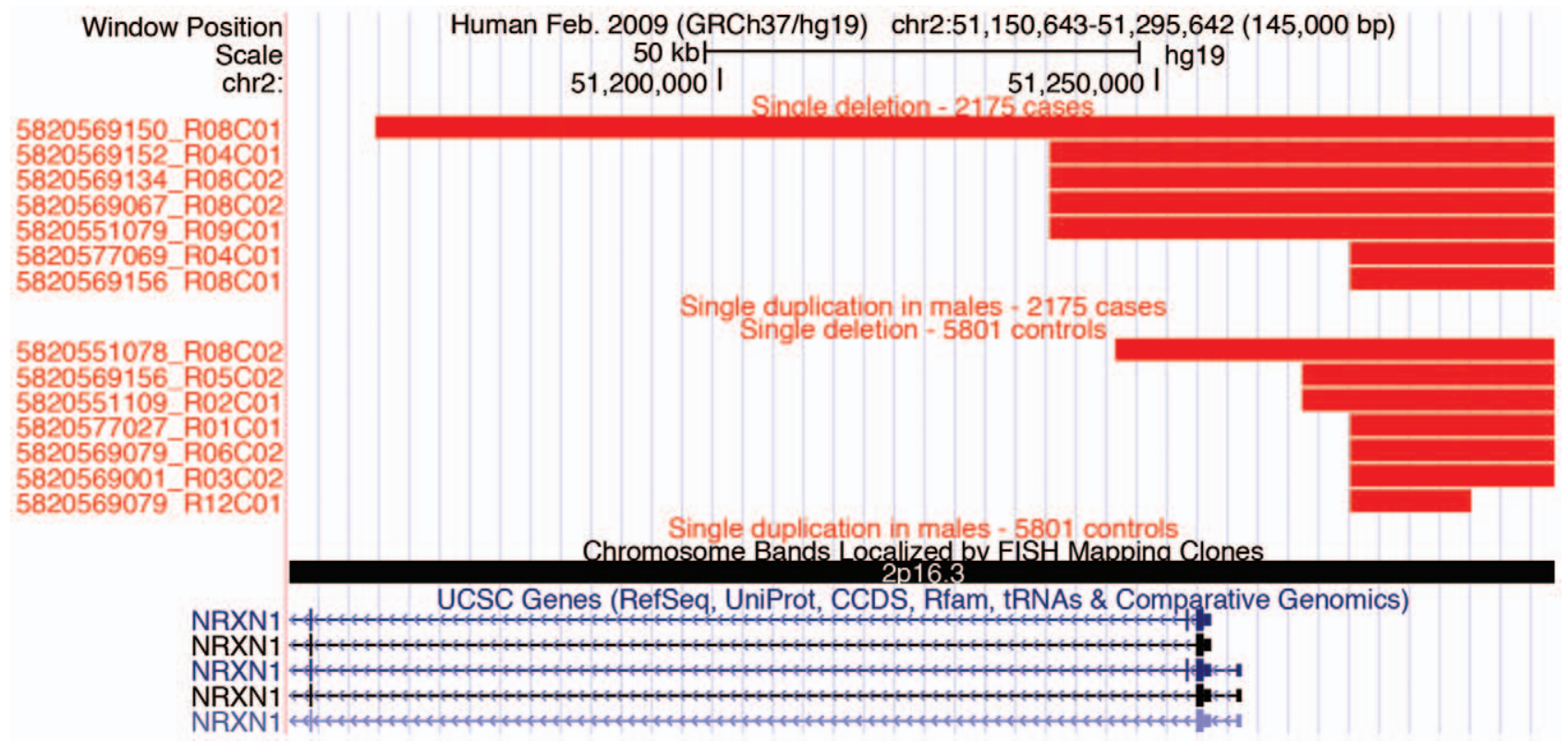

Figure 3. UCSC Genome browser view of CNVs in the NRXN1 region. CNVs observed in the vicinity of the NRXN1-alpha transcription start site are shown. Note that most CNVs observed in ASD patients include exon 1 of NRXN1-alpha while only 1 control CNV extends into exon 1. Produced with custom tracks listing CNV calls and uploaded to http://genome.ucsc.edu.

doi:10.1371/journal.pone.0052239.g003

\section{Published CNVs}

Additional CNVs from the literature and both published and unpublished CNVs identified at CHOP also were observed in our large dataset and met our criteria for potential clinical utility. Of those, 31 high-impact CNVs are shown in Table 4. All CNVs not previously experimentally validated were validated in this study.

One of the previously unpublished CHOP CNVs is a duplication that encompasses the $3^{\prime}$-end $R G S 20$ gene as well as the $3^{\prime}$-end of the TCEA1 gene. The RGS gene family encodes proteins that regulate G-protein signaling. These proteins function by increasing the inherent GTPase activity of their target Gproteins, and thus limit the signaling activity of their target Gproteins by keeping them in the inactive, GDP-bound state. RGS20 is expressed throughout the brain (reviewed in [45]), making it a likely candidate for involvement in neurological development. The TCEA1 gene, which also is partially encompassed by this $\mathrm{CNV}$, is a transcription elongation factor involved in RNA polymerase II transcription. A role for TCEAl in cell growth regulation has been suggested [46]. This potential role is consistent with the involvement of TCEA1 CNVs in ASD etiology as well.

\section{Pathway analysis}

Analysis of 104 genes within or immediately flanking our PCRvalidated $\mathrm{CNVs}$ yielded significant association of these genes to previously characterized functional networks. The five most statistically significant networks, along with their statistical scores, are shown in Table 5. The top ranking functional categories identified in this analysis, along with their P-values, are shown in Table 6.

As expected for CNVs associated with a neurodevelopmental disorder, a significant number of genes in or adjacent to the GNVs described here are involved in neural function, development and disease (Tables 5-6). Examples of such genes include: GABRA5, GABRA3, GABRG3, UBE3A, E2F1, PLCB1, PMP22, AADAT, MAPK3, NRXN1, NRG3, DPP10, UQCRC2, USH2A, NECAB3,
CNTN4, LINGO2, IL1RAPL1, STXBP5, DOC2A, and SNRPN. Of these genes, E2F1, AADAT, NECAB3, and IL1RAPL1 are not found in the Autism Chromosome Rearrangement Database (http://projects.tcag.ca/autism/), suggesting that they may be novel ASD risk genes.

The novel ASD risk loci identified here have functions that suggest a significant role in brain function and architecture. As such, altering the function of each of these genes as a result of the GNV could impinge on the biochemical pathways that are relevant to ASD etiology.

For example, mutations in IL1RAPL1 have been observed in cases of X-linked intellectual disability [47], and the encoded protein has been shown to play a role in voltage-gated calcium channel regulation in cultured cells [48]. E2F1 encodes a transcription factor and DNA-binding protein that plays a significant role in regulating cell growth and differentiation, apoptosis and response to DNA damage (reviewed in Biswas and Johnson, 2012 [49]). Each of these genes thus could have detrimental impacts on normal brain function.

$\mathcal{N E C A B 3}$ encodes a neuronal protein with two isoforms that regulate the production of beta-amyloid peptide in opposite directions, depending on whether exon 9 of $\mathcal{N} E C A B 3$ is included in or excluded from the mature mRNA [50].

$A A D A T$ encodes an aminotransferase with multiple functions, one of which leads to the synthesis of kynurenic acid. This pathway has been proposed as a target for potential neuroprotective therapeutics, indicating the potential significance of this finding for ASD etiology (reviewed in Stone et al., 2012 [51]). The specific roles that any of these genes play in ASD etiology have yet to be determined, but the observed neurological functions of their encoded proteins strongly support a potential role in normal brain function.

Many of these genes also have been implicated in other nervous system disorders, including Huntington's, Parkinson's, and Alzheimer's diseases as well as schizophrenia and epilepsy [41,52-61]. One of the features common to this group of 
Table 4. Published CNVs observed in our sample population.

\begin{tabular}{|c|c|c|c|c|c|c|c|c|c|c|c|}
\hline $\begin{array}{l}\text { Cyto } \\
\text { band }\end{array}$ & $\begin{array}{l}\text { Literature } \\
\text { CNVs }\end{array}$ & $\begin{array}{l}\text { Region of } \\
\text { Highest } \\
\text { Significance }\end{array}$ & $\begin{array}{l}\text { CNV } \\
\text { Type }\end{array}$ & $\begin{array}{l}\text { TaqMan } \\
\text { Validation }\end{array}$ & $\begin{array}{l}\text { Total } \\
\text { Cases }\end{array}$ & $\begin{array}{l}\text { Total } \\
\text { Controls }\end{array}$ & $\begin{array}{l}\text { Odds } \\
\text { Ratio }\end{array}$ & P Value & Cases & Controls & Gene/Region \\
\hline $1 q 21.1$ & $\begin{array}{l}\text { chr1:146555186- } \\
147779086\end{array}$ & $\begin{array}{l}\text { chr1:146656292- } \\
146707824\end{array}$ & Dup & NT & 1543 & 5761 & 7.48 & $1.15 \mathrm{E}-01$ & 2 & 1 & FMO5 \\
\hline $2 \mathrm{p} 24.3$ & $\begin{array}{l}\text { chr2:13202218- } \\
13248445\end{array}$ & $\begin{array}{l}\text { chr2:13203874- } \\
13209245\end{array}$ & Del & $\begin{array}{l}\text { Validated } \\
\text { (chr2:13203874- } \\
\text { 13209245) }\end{array}$ & 1544 & 5761 & $\infty$ & $2.11 \mathrm{E}-01$ & 1 & 0 & $\begin{array}{l}\text { upstream of } \\
\text { LOC100506474 }\end{array}$ \\
\hline $2 \mathrm{p} 21$ & $\begin{array}{l}\text { chr2:45455651- } \\
45984915\end{array}$ & $\begin{array}{l}\text { chr2:45489954- } \\
45492582\end{array}$ & Dup & NT & 1541 & 5756 & $\infty$ & $4.46 \mathrm{E}-02$ & 2 & 0 & $\begin{array}{l}\text { between UNQ } \\
6975 \text { and SRBD1 }\end{array}$ \\
\hline $2 \mathrm{p} 16.3$ & $\begin{array}{l}\text { chr2:50145644- } \\
51259671\end{array}$ & $\begin{array}{l}\text { chr2:51237767- } \\
51245359\end{array}$ & Del & NT & 1544 & 5762 & $\infty$ & $1.99 \mathrm{E}-03$ & 4 & 0 & NRXN1 \\
\hline 2p15 & $\begin{array}{l}\text { chr2:62258231- } \\
63028717\end{array}$ & $\begin{array}{l}\text { chr2:62230970- } \\
62367720\end{array}$ & Dup & NT & 1543 & 5762 & $\infty$ & $2.11 \mathrm{E}-01$ & 1 & 0 & COMMD1 \\
\hline $2 q 14.1$ & $\begin{array}{l}\text { chr2:115139568- } \\
115617934\end{array}$ & $\begin{array}{l}\text { chr2:115133493- } \\
115140263\end{array}$ & Del & NT & 1543 & 5759 & 7.47 & $1.15 \mathrm{E}-01$ & 2 & 1 & $\begin{array}{l}\text { between } \\
\text { LOC } 440900 \text { and } \\
\text { DPP10 }\end{array}$ \\
\hline $3 p 26.3$ & $\begin{array}{l}\text { chr3:1940192- } \\
1940920\end{array}$ & $\begin{array}{l}\text { chr3:1937796- } \\
\text { 1941004 }\end{array}$ & Del & $\begin{array}{l}\text { Validated } \\
\text { (chr3:1937796- } \\
\text { 1942764) }\end{array}$ & 1544 & 5760 & 5.60 & $6.70 \mathrm{E}-02$ & 3 & 2 & $\begin{array}{l}\text { between CNTN6 } \\
\text { and CNTN4 }\end{array}$ \\
\hline 3p14.1 & $\begin{array}{l}\text { chr3:67656832- } \\
68957204\end{array}$ & $\begin{array}{l}\text { chr3:67657429- } \\
68962928\end{array}$ & Del & NT & 1544 & 5762 & $\infty$ & $2.11 \mathrm{E}-01$ & 1 & 0 & $\begin{array}{l}\text { SUCLG2, FAM19A4, } \\
\text { FAM19A1 }\end{array}$ \\
\hline $4 q 13.3$ & $\begin{array}{l}\text { chr4:73756500- } \\
73905356\end{array}$ & $\begin{array}{l}\text { chr4:73766964- } \\
73816870\end{array}$ & Dup & $\begin{array}{l}\text { Validated } \\
\text { (chr4:73753294- } \\
\text { 74058988) }\end{array}$ & 1544 & 5760 & $\infty$ & $2.11 \mathrm{E}-01$ & 1 & 0 & COX18, ANKRD17 \\
\hline $4 q 33$ & $\begin{array}{l}\text { chr4:154087652- } \\
172339893\end{array}$ & $\begin{array}{l}\text { chr4:171366005- } \\
171471530\end{array}$ & Del & NT & 1543 & 5761 & $\infty$ & 4.46E-02 & 2 & 0 & $\begin{array}{l}\text { between AADAT } \\
\text { and HSP90AA6P }\end{array}$ \\
\hline $5 q 23.1$ & $\begin{array}{l}\text { chr5:118478541- } \\
118584821\end{array}$ & $\begin{array}{l}\text { chr5:118527524- } \\
118589485\end{array}$ & Dup & $\begin{array}{l}\text { Validated } \\
\text { (chr5:118527524- } \\
118614781 \text { ) }\end{array}$ & 1541 & 5760 & 3.74 & $1.98 \mathrm{E}-01$ & 2 & 2 & DMXL1, TNFAIP8 \\
\hline $6 p 21.2$ & $\begin{array}{l}\text { chr6:39071841- } \\
39082863\end{array}$ & $\begin{array}{l}\text { chr6:39069291- } \\
39072241\end{array}$ & Del & $\begin{array}{l}\text { Validated } \\
\text { (chr6:39069291- } \\
\text { 39072241) }\end{array}$ & 1544 & 5759 & 2.37 & $1.93 \mathrm{E}-02$ & 12 & 19 & SAYSD1 \\
\hline $8 q 11.23$ & $\begin{array}{l}\text { chr8:54858496- } \\
54907579\end{array}$ & $\begin{array}{l}\text { chr8:54855680- } \\
54912001\end{array}$ & Dup & $\begin{array}{l}\text { Validated } \\
\text { (chr8:54855680- } \\
\text { 54912001) }\end{array}$ & 1544 & 5762 & $\infty$ & $2.11 \mathrm{E}-01$ & 1 & 0 & RGS20, TCEA1 \\
\hline $10 q 11.22$ & $\begin{array}{l}\text { chr10:46269076- } \\
50892143\end{array}$ & $\begin{array}{l}\text { chr10:49370090- } \\
49471091\end{array}$ & Dup & NT & 1528 & 5750 & 3.77 & $1.96 \mathrm{E}-01$ & 2 & 2 & $\begin{array}{l}\text { FRMPD2P1, } \\
\text { FRMPD2 }\end{array}$ \\
\hline $10 q 11.23$ & $\begin{array}{l}\text { chr10:50892146- } \\
51450787\end{array}$ & $\begin{array}{l}\text { chr10:50884949- } \\
50943185\end{array}$ & Dup & NT & 1542 & 5760 & 3.74 & $1.98 \mathrm{E}-01$ & 2 & 2 & OGDHL, C10orf53 \\
\hline $12 q 13.13$ & $\begin{array}{l}\text { chr12:53183470- } \\
53189890\end{array}$ & $\begin{array}{l}\text { chr12:53177144- } \\
53180552\end{array}$ & Del & $\begin{array}{l}\text { Validated } \\
\text { (chr12:53177144- } \\
53182177 \text { ) }\end{array}$ & 1544 & 5762 & $\infty$ & $4.46 \mathrm{E}-02$ & 2 & 0 & $\begin{array}{l}\text { between KRT76 } \\
\text { and KRT3 }\end{array}$ \\
\hline $15 q 11.1$ & $\begin{array}{l}\text { chr15:20266959- } \\
25480660\end{array}$ & $\begin{array}{l}\text { chr15:20192970- } \\
\text { 20197164 }\end{array}$ & Dup & $\begin{array}{l}\text { Validated } \\
\text { (chr15:20192970- } \\
\text { 20212798) }\end{array}$ & 1515 & 5632 & 4.97 & $4.06 \mathrm{E}-02$ & 4 & 3 & $\begin{array}{l}\text { downstream of } \\
\text { HERC2P3 }\end{array}$ \\
\hline $15 q 11.2$ & $\begin{array}{l}\text { chr15:20266959- } \\
25480660\end{array}$ & $\begin{array}{l}\text { chr15:25099351- } \\
25102073\end{array}$ & Del & NT & 1540 & 5761 & 3.75 & $1.13 \mathrm{E}-01$ & 3 & 3 & SNRPN \\
\hline $15 q 11.2$ & $\begin{array}{l}\text { chr15:20266959- } \\
25480660\end{array}$ & $\begin{array}{l}\text { chr15:25099351- } \\
25102073\end{array}$ & Dup & NT & 1541 & 5759 & 45.19 & 7.93E-08 & 12 & 1 & SNRPN \\
\hline $15 q 11.2$ & $\begin{array}{l}\text { chr15:25582397- } \\
25684125\end{array}$ & $\begin{array}{l}\text { chr15:25579767- } \\
25581658\end{array}$ & Dup* & $\begin{array}{l}\text { Validated } \\
\text { (chr15:25576642- } \\
\text { 25581880) }\end{array}$ & 1540 & 5761 & $\infty$ & $3.86 \mathrm{E}-06$ & 8 & 0 & $\begin{array}{l}\text { between } \\
\text { SNORD109A } \\
\text { and UBE3A }\end{array}$ \\
\hline $15 q 11.2$ & $\begin{array}{l}\text { chr15:25582397- } \\
25684125\end{array}$ & $\begin{array}{l}\text { chr15:25582882- } \\
25662988\end{array}$ & Dup* & NT & 1540 & 5762 & 30.08 & $2.82 \mathrm{E}-05$ & 8 & 1 & UBE3A \\
\hline $16 p 12.2$ & $\begin{array}{l}\text { chr16:21901310- } \\
22703860\end{array}$ & $\begin{array}{l}\text { chr16:21958486- } \\
22172866\end{array}$ & Dup & NT & 1544 & 5761 & $\infty$ & 4.47E-02 & 2 & 0 & $\begin{array}{l}\text { C16orf52, UQCRC2, } \\
\text { PDZD9, VWA3A }\end{array}$ \\
\hline
\end{tabular}


Table 4. Cont.

\begin{tabular}{|c|c|c|c|c|c|c|c|c|c|c|c|}
\hline $\begin{array}{l}\text { Cyto } \\
\text { band }\end{array}$ & $\begin{array}{l}\text { Literature } \\
\text { CNVs }\end{array}$ & $\begin{array}{l}\text { Region of } \\
\text { Highest } \\
\text { Significance }\end{array}$ & $\begin{array}{l}\text { CNV } \\
\text { Type }\end{array}$ & $\begin{array}{l}\text { TaqMan } \\
\text { Validation }\end{array}$ & $\begin{array}{l}\text { Total } \\
\text { Cases }\end{array}$ & $\begin{array}{l}\text { Total } \\
\text { Controls }\end{array}$ & $\begin{array}{l}\text { Odds } \\
\text { Ratio }\end{array}$ & P Value & Cases & Controls & Gene/Region \\
\hline 16p11.2 & $\begin{array}{l}\text { chr16:29671216- } \\
30173786\end{array}$ & $\begin{array}{l}\text { chr16:29664753- } \\
30177298\end{array}$ & Del & NT & 1544 & 5761 & 7.47 & $1.15 \mathrm{E}-01$ & 2 & 1 & $\begin{array}{l}\text { DOC2A, ASPHD1, } \\
\text { LOC440356, TBX6, } \\
\text { LOC100271831, } \\
\text { PRRT2, CDIPT, } \\
\text { QPRT, YPEL3, } \\
\text { PPP4C, MAPK3, } \\
\text { SPN, MVP, FAM57B, } \\
\text { ZG16, ALDOA, } \\
\text { INO80E, SEZ6L2, } \\
\text { TAOK2, KCTD13, } \\
\text { MAZ, KIF22, GDPD3, } \\
\text { C16orf92, C16orf53, } \\
\text { TMEM219, } \\
\text { C16orf54, HIRIP3 }\end{array}$ \\
\hline $16 q 23.3$ & $\begin{array}{l}\text { chr16:82195236- } \\
82722082\end{array}$ & $\begin{array}{l}\text { chr16:82423855- } \\
82445055\end{array}$ & Dup & NT & 1542 & 5758 & $\infty$ & $4.46 \mathrm{E}-02$ & 2 & 0 & $\begin{array}{l}\text { between } \\
\text { MPHOSPH6 and } \\
\text { CDH13 }\end{array}$ \\
\hline 17p12 & $\begin{array}{l}\text { chr17:14139846- } \\
15282723\end{array}$ & $\begin{array}{l}\text { chr17:14132271- } \\
14133349\end{array}$ & Dup & $\begin{array}{l}\text { Validated } \\
\text { (chr17:14132271- } \\
\text { 14133568) }\end{array}$ & 1544 & 5762 & 1.60 & 3.57E-01 & 3 & 7 & $\begin{array}{l}\text { between COX10 } \\
\text { and CDRT15 }\end{array}$ \\
\hline 17p12 & $\begin{array}{l}\text { chr17:14139846- } \\
15282723\end{array}$ & $\begin{array}{l}\text { chr17:14132271- } \\
15282708\end{array}$ & Del & NT & 1544 & 5761 & 5.61 & $6.70 \mathrm{E}-02$ & 3 & 2 & $\begin{array}{l}\text { PMP22, CDRT15, } \\
\text { TEKT3, MGC12916, } \\
\text { CDRT7, HS3ST3B1 }\end{array}$ \\
\hline $17 \mathrm{p} 12$ & $\begin{array}{l}\text { chr17:14139846- } \\
15282723\end{array}$ & $\begin{array}{l}\text { chr17:14952999- } \\
15053648\end{array}$ & Dup & NT & 1543 & 5760 & 3.74 & $1.98 \mathrm{E}-01$ & 2 & 2 & $\begin{array}{l}\text { between CDRT7 } \\
\text { and PMP22 }\end{array}$ \\
\hline 17p12 & $\begin{array}{l}\text { chr17:14139846- } \\
15282723\end{array}$ & $\begin{array}{l}\text { chr17:15283960- } \\
15287134\end{array}$ & Del & $\begin{array}{l}\text { Validated } \\
\text { (chr17:15283960- } \\
15287134 \text { ) }\end{array}$ & 1544 & 5761 & 3.74 & $1.13 \mathrm{E}-01$ & 3 & 3 & $\begin{array}{l}\text { between TEKT3 and } \\
\text { FAM18B2-CDRT4 }\end{array}$ \\
\hline 20p12.3 & $\begin{array}{l}\text { chr20:8044044- } \\
8527513\end{array}$ & $\begin{array}{l}\text { chr20:8162278- } \\
8313229\end{array}$ & Dup & NT & 1544 & 5761 & 3.73 & $1.98 \mathrm{E}-01$ & 2 & 2 & PLCB1 \\
\hline Xp21.2 & $\begin{array}{l}\text { chrX:28605682- } \\
29974014\end{array}$ & $\begin{array}{l}\text { chrX:29944502- } \\
29987870\end{array}$ & Dup & NT & 1544 & 5760 & $\infty$ & 4.47E-02 & 2 & 0 & IL1RAPL1 \\
\hline Xq27.2 & $\begin{array}{l}\text { chrX:139998330- } \\
140443613\end{array}$ & $\begin{array}{l}\text { chrX:140329633- } \\
140348506\end{array}$ & Del & $\begin{array}{l}\text { Validated } \\
\text { (chrX:140329633- } \\
\text { 140456325) }\end{array}$ & 1544 & 5762 & 7.48 & $2.06 \mathrm{E}-02$ & 4 & 2 & SPANXC \\
\hline Xq28 & $\begin{array}{l}\text { chrX:148858522- } \\
149097275\end{array}$ & $\begin{array}{l}\text { chrX:148882559- } \\
148886166\end{array}$ & Del & $\begin{array}{l}\text { Validated } \\
\text { (chrX:148882559- } \\
\text { 149020410) }\end{array}$ & 1540 & 5754 & $\infty$ & 4.46E-02 & 2 & 0 & MAGEA8 \\
\hline
\end{tabular}

*Denotes CNVs contiguous with the chromosome 15q11.2-13.1 CNV shown in Table 3.

doi:10.1371/journal.pone.0052239.t004

disorders, which includes ASD, is synaptic dysfunction. There is a significant overlap in genes, and/or the molecular mechanisms by which these genes give rise to synaptopathies (reviewed in [62]). We therefore find it notable that many such genes involved in other synaptopathies were found within or flanking the validated GNVs we identified as associated with ASD.

In addition to neurogenic genes, validated CNVs were associated with genes with known roles in renal and cardiovascular diseases (Table 6). Several syndromic forms of autism, such as DiGeorge Syndrome and Charcot-Marie Tooth Disease are comorbid with renal and cardiovascular disease, and therefore it was not surprising to find that our study identified CNVs containing genes associated with these syndromes and functions, such as CDRT15, and CDH13.

There is mounting evidence, as well, that inflammatory responses are involved with the development and progression of autism (reviewed in [63]). Maternal immune activation during pregnancy is believed to activate fetal inflammatory responses, in some cases with detrimental effects on neural development in the fetus, leading to autism. This environmental insult could be mediated or enhanced by genomic changes that predispose the fetus to elevated inflammatory responses, so it is significant that a number of genes from our validated CNVs play a role in inflammatory response. Examples of these include CD160, CALCR, and $S P \mathcal{N}$.

Our findings are consistent with other studies that used pathway analysis to characterize the genes contained in ASD risk GNVs, and suggest that many different biological pathways, when disrupted, can lead to features observed in ASD. The wide variety of biological functions identified for these genes also is consistent with estimates of the number of independent genetic variants that may play a role in the etiology of ASD (8-11).

\section{Discussion}

We used a custom microarray to characterize the frequency of CNVs identified in high-risk ASD families in a large ASD case/ control population. We also evaluated further the frequency of GNVs discovered in several published studies in our sample cohort to obtain a clearer picture of the potential clinical utility of these 


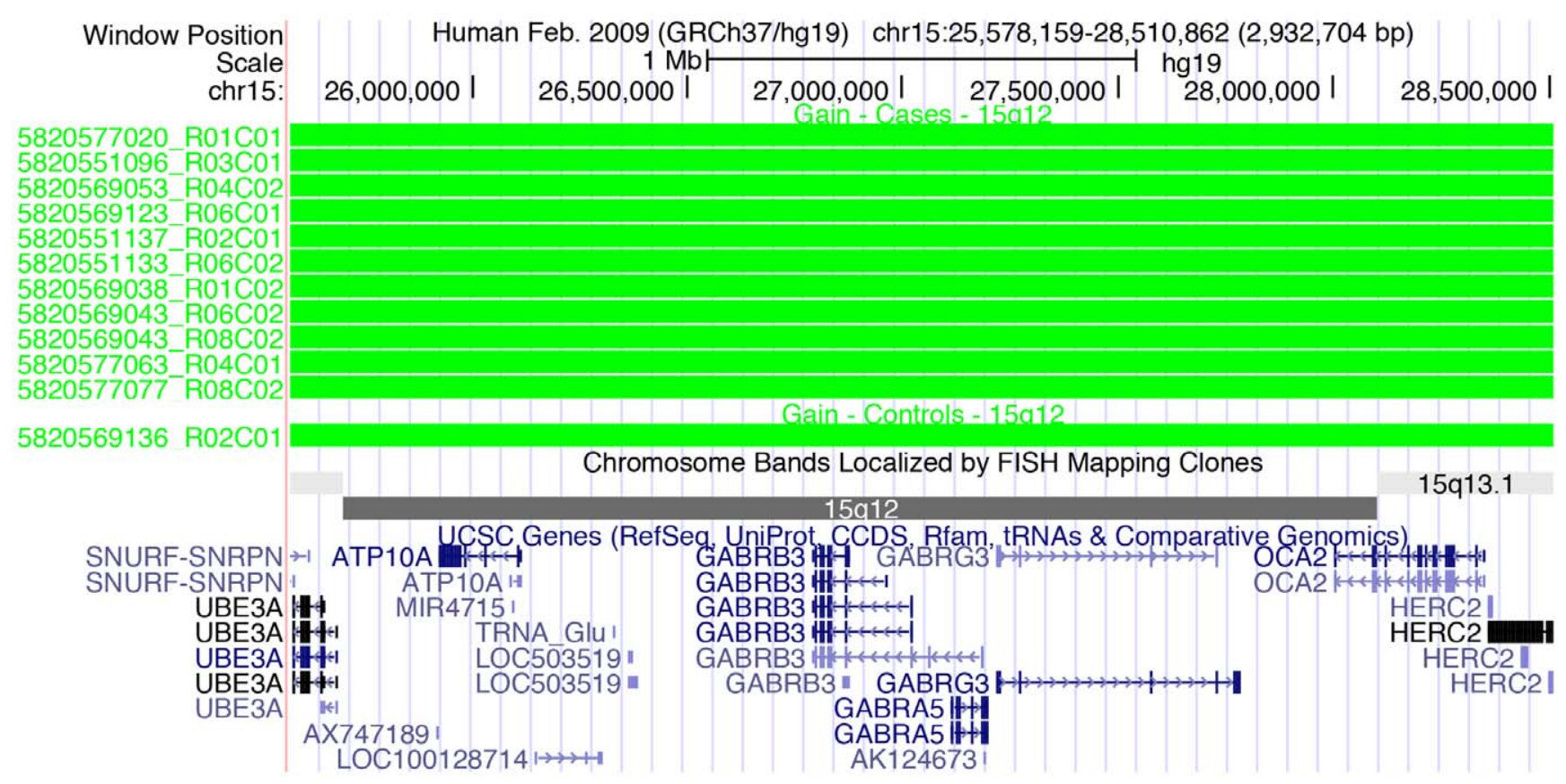

Figure 4. UCSC Genome Browser View of CNVs in the GABR Region on chromosome 15q12. Duplications were called by both PennCNV and by CNAM in this region, however the number of duplications called by each program differed, with many additional duplications called by CNAM. Produced with custom tracks listing CNV calls and uploaded to http://genome.ucsc.edu. doi:10.1371/journal.pone.0052239.g004

CNVs in the genetic evaluation of children with ASD. We used multiple quality control measures to insure that all cases and controls a) had no unexpected familial relationships; b) represented a uniform ethnic group; c) were devoid of uncharacterized whole chromosome anomalies or other genomic abnormalities consistent with syndromic forms of ASD; d) had sufficient power to distinguish risk variants from CNVs with little or no impact on the ASD phenotype; and e) were validated using quantitative PCR even though the custom array used here represented at least a second evaluation for most of them. Parents of ASD cases tested were not available to determine state of inheritance.

The validity of our approach was confirmed by our observation of CNVs that had been previously identified as ASD risked markers, including CNVs encompassing parts of the $\mathcal{N R X N 1}$ gene. GNVs and point mutations in $\mathcal{N R X N 1}$ are thought to play a role in a subset of ASD cases as well as in other neuropsychiatric conditions $[15,32,36-40]$. The data from our study demonstrate that $\mathcal{N R X N 1}$ GNVs also occur in high-risk ASD families. Further, our case/control data provide additional evidence that neurexin-1 plays an important role in unrelated ASD cases. While CNVs near
NRXN1 occur in controls as well as in cases, the CVNs observed in our ASD cases typically disrupt a portion of the $\mathcal{N} R X N 1$ coding region while $\mathrm{GNV}$ s observed in our control population do not.

\section{CNVs from high-risk ASD families}

In our high-risk ASD families, we identified both novel and previously observed $\mathrm{CNVs}$ containing genes with potential relevance to neuropsychiatric conditions such as ASD. These include $\mathrm{CNV}$ s involving $L I N G O 2$, the GABR gene cluster on chromosome $15 \mathrm{q} 12$ and STXBP5. Each of these CNV regions has an odds ratio greater than 2 and most of the GNVs we identified in high-risk families have a significant $\mathrm{p}$ value associating them with the ASD phenotype in this case/control study. Some GNVs, although observed only in ASD cases and not in controls, were too rare even in this large dataset to generate statistically significant results. An example is a deletion involving STXBP5 that was observed two ASD samples and in no controls. A deletion including this gene was previously observed in a patient with an apparent syndromic form of ASD [64], lending further support to our observation of STXBP5 deletions in ASD cases. These data

Table 5. Top Significant Networks Identified by Pathway Analysis using Ingenuity IPA.

\begin{tabular}{lll}
\hline Network & Score \\
\hline Cell-To-Cell Signaling and Interaction, Tissue Development, Gene Expression & 55 \\
Neurological Disease, Behavior, Cardiovascular Disease & 28 \\
Cell Death, Cellular Compromise, Neurological Disease & 26 \\
Cellular Development, Cell Morphology, Nervous System Development and Function & 20 \\
Behavior, Cardiovascular Disease, Neurological Disease & 18 \\
\hline
\end{tabular}

Network scores are the $-\log \mathrm{P}$ for the results of a right-tailed Fisher's Exact Test.

doi:10.1371/journal.pone.0052239.t005 
Table 6. Top Significant Biological Functions identified by Ingenuity IPA and literature searches.

\begin{tabular}{|c|c|c|}
\hline Function & p-value range & \# Genes \\
\hline Neurological Disease & $2.71 \mathrm{E}-05-3.15 \mathrm{E}-02$ & $14(18)$ \\
\hline Behavior & $5.93 \mathrm{E}-05-4.36 \mathrm{E}-02$ & 10 \\
\hline Cardiovascular Disease & $8.58 \mathrm{E}-05-4.30 \mathrm{E}-02$ & 10 \\
\hline Cellular Development & $1.39 \mathrm{E}-04-4.77 \mathrm{E}-02$ & 9 \\
\hline Inflammatory response & $4.84 \mathrm{E}-04-2.89 \mathrm{E}-02$ & 6 \\
\hline \multicolumn{3}{|c|}{$\begin{array}{l}\text { The right-tailed Fisher's exact test was used to calculate P-values representin } \\
\text { the probability that selecting genes associated with that pathway or network } \\
\text { due to chance alone. Each functional category represents a collection of } \\
\text { associated subcategories, each of which has an associated P-value. For exampl } \\
\text { within 'Neurological Disease,' are subcategories of genes associated with } \\
\text { seizures, Huntington Disease, schizophrenia, etc. The P-value range given } \\
\text { represents the range of P-values generated for each subcategory. In the first } \\
\text { line, } 14 \text { genes were associated with a function in Neurological Disease by } \\
\text { Ingenuity software. An additional } 4 \text { genes were identified as having } \\
\text { neurological functions in the literature, giving a total of } 18 \text { with known or } \\
\text { suspected roles in neurological disease. } \\
\text { doi:10.1371/journal.pone.0052239.t006 }\end{array}$} \\
\hline
\end{tabular}

collectively suggest that GNVs observed in high-risk ASD families also are important contributors to the etiology of ASD in an ASD case/control population.

We detected rare duplications involving the GABA receptor gene cluster as well as additional genes in the Prader-Willi/ Angelman syndrome region on chromosome 15 (11/1,544 unrelated cases, 1/5,762 unrelated controls, OR $=40.05)$. All of these CNVs were confirmed using TaqMan assays spanning the region, and these results strongly suggest a role for duplications on chromosome $15 \mathrm{q} 12$ in ASD etiology. Deficiency of $\mathrm{GABA}_{\mathrm{A}}$ receptors indeed is thought to play an important role in both autism and epilepsy, and duplications have been observed to result in decreased GABR expression through a potential epigenetic mechanism (reviewed in [65]). Further, differences in the expression of GABRB3 mRNA and protein in the brains of some children with autism have been reported along with loss of biallelic expression of the chromosome $15 \mathrm{q}$ GABR genes in some individuals, [66], suggesting that epigenetic regulation of the chromosome 15 GABR gene cluster could also contribute to ASD etiology. Consistent with many previous findings from family studies, case reports and modest case/control studies (http:// omim.org/entry/608636), our data provide additional support for the involvement of duplications in this region of the genome in ASD. Further, our large population study suggests that these duplications may explain as much as $0.7 \%$ of ASD cases.

A recent study searching for GNVs encompassing genes in the GABA pathway, including the chromosome 15 GABR gene cluster, also found CNVs in this region. In contrast to our findings, this study found GABR gene cluster duplications at similar frequencies in both cases and in controls (Table S2 in ref. [44]). In addition, deletions were more common in this study in both cases and controls, while duplications were more common in our data. The differences between the two studies may lie in the sample population being studied, the uniformity of our sample population, or the technology platform used for CNV discovery (custom Illumina array compared to a custom Agilent array). Previous results have demonstrated maternal inheritance of deletions in this region in children with autism [67]. However, in our family studies we did not observe CNVs involving chromosome $15 \mathrm{q} 12$, and our case/control data preclude us from determining the parent of origin.
Interestingly, the CNVs that we observed on chromosome $15 \mathrm{q}$ were detected primarily with probes for SNVs identified in the GABR genes. Further, these SNVs were identified in affected individuals from high-risk ASD families. We did not observe CNVs involving this region in our high-risk ASD families. The observation of frequent duplications in our case/control population in the region containing these genes, coupled with the detection of these $\mathrm{CNV}_{\mathrm{s}}$ using probes for potential detrimental single nucleotide variants, suggests that both SNVs and CNVs involving the GABR genes might be pathogenic.

\section{Literature supported CNVs}

In addition to the CVNs identified in our high-risk ASD families, we evaluated further ASD risk $\mathrm{CNV}$ s identified in previous studies. Our results (Table 4) clearly demonstrate a role for many of these CNVs in ASD pathogenesis. Consistent with previous results, our data demonstrate in a large ASD population that rare GNVs are likely to play a role in the genetics of ASD, and suggest that these CNVs should be included in the genetic evaluation of children with ASD.

Interestingly, recent publications have identified a recurrent duplication of the Williams syndrome region on chromosome $7 q 11.23$ in children with ASD [9,11]. We included probes for this region on our custom array, and were not able to identify any $7 q 11.23$ duplications in our datasets. The reason(s) we did not observe any duplications in this region is not obvious; we had adequate probe coverage to have seen such duplications if they were present. Similar to the simplex ASD families used in those published studies, most of our ASD samples also were from reported simplex families, so the lack of observation of these GNVs is unlikely to be due to differences in family structure.

A CNV discovered at CHOP and not previously published includes a portion of the LCE gene cluster on chromosome 1 . Deletions in this region have been associated with psoriasis $[68,69]$, but no variants in this region have been linked to autism. Focusing solely on individuals of northern and western European ancestry, we observed this CNV deletion in a single case and also a single control. However, when we included samples of nonEuropean or uncertain ancestry, we observed 27 additional case DNA samples that carried this deletion, while only a single additional CNV-positive control was observed. Interestingly, based on SNP genotype results from principal component analysis, all of the cases that were positive for this CNV were of Asian descent. Since our control cohort had few individuals of Asian descent, we suspected that this CNV might be common in the Asian population. Analysis of whole genome data for individuals of non- European ancestry genotyped at the Center for Applied Genomics did not demonstrate common GNVs in either cases or controls in this region in individuals with Asian ancestry. However, a common CNV including LCE3E was observed in individuals with African ancestry (unpublished observations). Further analysis will be necessary to determine if this $\mathrm{CNV}$ is an ASD risk variant in either Asian or African populations.

\section{Effect of analysis method on CNV validation}

Although some GNVs are described here for the first time, many of the GNVs that we evaluated in this study were described previously. It is interesting to note that individual CNV calls that were made with both of the software packages we used were much more likely to be validated by qPCR than were GNVs called by either program alone. In fact, $97 \%$ of the CNVs called by both PennCNV and CNAM validated using TaqMan qPCR assays, while only $24 \%$ of the CNVs called by PennCNV alone and $30 \%$ of the GNVs called by CNAM alone were validated using the same 
approach. The concordance between the two analysis methods is informative given that the final sample sets used by the two methods differed substantially. The CNAM analysis used 290 fewer case samples and 575 fewer control samples than the PennCNV analysis. These data clearly demonstrate the value of using multiple software packages to evaluate microarray data for CNV discovery work. Our data are consistent with the rarity of many GNVs detected in DNA from children with ASD, and with the suggestion that there may be hundreds of loci that contribute to the development of ASD [9,11].

Our data demonstrate that GNVs identified in high-risk ASD families play a role in the etiology of ASD in unrelated cases. Evaluation of these CNVs in the large sample set used in this study provides compelling evidence for extremely rare recurrent CNVs as well as additional common variants in the genetics of ASD. We suggest that the CNVs described here likely have a strong impact on the development of ASD. Given the extensive quality control measures we used to characterize our sample cohort, the frequency at which we observed these GNVs in our cohort, and the molecular validation that we used to verify the calls, these CNVs can be used to increase sensitivity in the genetic evaluation of children with ASD. Further work will help to determine if the CNVs reported here are important for specific clinical subsets of ASD cases.

\section{Materials and Methods}

\section{Ethics statement}

The research presented here has been approved by the University of Utah Institutional Review Board (IRB) (University of Utah IRB\#:6042-96) and the Children's Hospital of Philadelphia IRB (CHOP IRB\#: IRB 06-004886). Patients and their families were recruited through the University of Utah Department of Psychiatry or the Children's Hospital of Philadelphia clinic or CHOP outreach clinics. Written informed consent was obtained from the participants or their parents using IRB approved consent forms prior to enrollment in the project. There was no discrimination against individuals or families who chose not to participate in the study. All data were analyzed anonymously and all clinical investigations were conducted according to the principles expressed in the Declaration of Helsinki.

\section{DNA samples}

DNA samples from high-risk ASD family members were collected through the University of Utah Department of Psychiatry. Three independent sample cohorts, comprising 3,000 ASD patient samples $(72 \%$ male), were collected for CNV replication. Of those, 857 samples were from probands recruited and genotyped by the Center for Applied Genomics (CAG) at CHOP from the greater Philadelphia area using a CHOP IRB-approved protocol; 2,143 ASD samples were from the AGRE and the AGP consortium (Rutgers, NJ ASD repository), and genotyped at the CAG center at CHOP (Table 1). Only samples from affected individuals diagnosed using the Autism Diagnostic InterviewRevised (ADI-R) and the Autism Diagnostic Observation Schedule (ADOS) were used in the study. All control samples were from CHOP and were matched in a 2:1 ratio with the ASD cases.

\section{CNV Discovery in high-risk ASD families}

DNA samples were genotyped on the Affymetrix Genome-Wide Human SNP Array 6.0 according to the manufacturer's protocol. Fifty-five autism subjects were chosen from 9 families with multiple affected first-degree relatives. The number of individuals with an autism diagnosis in these families ranged from 3 to 9. Affected individuals were diagnosed using ADI-R and ADOS. Control subjects $(\mathrm{N}=439)$ for the discovery phase of the project were selected from Utah CEPH/Genetics Reference Project (UGRP) families [70]. All microarray experiments were performed on blood DNA samples, except for two of the 55 case samples and three control subjects for which DNA from lymphoblastoid cell lines was used. CNVs were initially detected using the Copy Number Analysis Module (GNAM) of Golden Helix SNP \& Variation Suite (SVS) (Golden Helix Inc.). Log ratios were calculated by quantile normalizing the $\mathrm{A}$ allele and $\mathrm{B}$ allele intensities using the entire population as a reference median for each SNP.

Batch effects in the log ratios were corrected via numeric principle component analysis (PCA) [71]. GNV segmentation analysis was carried out for each individual using the univariate CNAM segmentation procedure of Golden Helix SVS. We used a moving window of 5,000 markers, maximum number of segments per window of 20, minimum segment size 10 markers, and pairwise permutation $\mathrm{p}$-value of 0.001 .

\section{iSelect array design}

Probes for each GNV to be characterized in this study were selected from the Illumina Omni2.5 array probe set. Probes were selected to be as uniformly spaced across each region and flanking each region as possible (using the hgl9 genome build). For each GNV, we included 10 or more probes within the defined CNV region $(\mathrm{CNVr})$ and five probes on each flank (except where not possible due to the telomeric location of a CNVr). Probes for an additional $185 \mathrm{CNVs}$ described in the literature, including 104 identified by CHOP in samples that partially overlap those used in this study, also were included for further GNV validation. We attempted to increase probe coverage for CNVs identified with only a small number of probes. Finally, we included probes for 2,799 putative functional candidate SNVs detected by targeted exome DNA sequencing on 26 representative individuals from 11 ASD families (unpublished data). The genes that we targeted for exome sequencing included all known genes in regions of familial haplotype sharing and linkage as well as additional autism candidate genes. These SNVs, although included in a search for potential ASD point mutations, also were used to identify additional CNVs.

\section{Array processing}

We performed high throughput SNP genotyping using the Illumina Infinium ${ }^{\mathrm{TM}}$ II BeadChip technology (Illumina, San Diego), at the Center for Applied Genomics at CHOP. Detailed methods for array processing are available in the associated Supplemental Materials.

\section{CNV calling and statistical analysis}

GNVs were called using both PennCNV [34][35] and GNAM (Golden Helix SNP \& Variation Suite (SVS), Golden Helix, Inc.). GNV calling using PennCNV was performed as described [32]. For CNAM calls, we chose not to examine whole chromosomes, but rather to analyze each target region separately. Since our array targeted specific regions and did not have probe coverage over much of the genome, it was desirable to avoid calling segments that spanned large regions with no data, and prevent any CNV calls from being influenced by distant data points. To accomplish this, the markers in the data set were grouped into "pseudochromosomes", one for each CNVr covered by the array, that were then considered individually in the segmentation algorithm. CNAM was run using the univariate option with no moving 
window, maximum of 5 segments per pseudochromosome, minimum segment size of 1 marker, and permutation p-value threshold of 0.001. After segmentation, we classified segments as losses, gains, or neutral. Fisher's exact test was used to test for association of copy number loss vs. no loss, and copy number gain vs. no gain. Similar tests were conducted for the $\mathrm{X}$ chromosome, stratified by gender. Odds ratios also were calculated as an indicator of potential clinical risk for each GNV.

\section{Laboratory confirmation of CNVs}

Array results were confirmed using pre-designed Applied Biosystems TaqMan copy number assays or custom-designed TaqMan copy number assays when necessary (Life Technologies, Inc.). All CNVs with odds ratios greater than 2.0 and present in at least two cases were selected for molecular validation. We did not select $\mathrm{CNV}$ s with odds ratios less than 2 for validation since we wanted to validate only those with high potential clinical utility. Six CNVs also were selected for validation because they were adjacent to, but not overlapping, literature CNVs that were covered by probes on the custom array. A maximum of 6 case samples were validated for each GNV. Five negative control samples, selected based on their lack of all of the CNVs under study also were included in each validation assay. A list of all of the TaqMan assays used in this work is found in Table S1 in File S1, and detailed procedures are described in File S2.

\section{Pathway analysis}

Analysis of biological pathways encompassing genes found in the CNV regions was performed using the bioinformatics tools DAVID Bioinformatics Resources 6.7 [72,73] and Ingenuity Pathways Analysis (IPA) (Ingenuity ${ }^{\circledR}$ Systems). We performed network and pathway analyses on genes contained within the CNVs or immediately flanking intergenic GNVs that were PCR validated. Pathway analysis details are described in File S2.

\section{Supporting Information}

File S1 Supplemental data Tables S1-S4. Table S1. TaqMan assays used for GNV confirmation. Genomic

\section{References}

1. Rosenberg RE, Law JK, Yenokyan G, McGready J, Kaufmann WE, et al. (2009) Characteristics and Concordance of Autism Spectrum Disorders Among 277 Twin PairsAutism Characteristics and Discordance in Twins. Arch Pediatr Adolesc Med 163: 907-914. doi:10.1001/archpediatrics.2009.98.

2. Hallmayer J, Cleveland S, Torres A, Phillips J, Cohen B, et al. (2011) Genetic Heritability and Shared Environmental Factors Among Twin Pairs With Autism. Arch Gen Psychiatry 68: 1095-1102. doi:10.1001/archgenpsychiatry. 2011.76 .

3. Lichtenstein P, Carlström E, Råstam M, Gillberg C, Anckarsäter H (2010) The Genetics of Autism Spectrum Disorders and Related Neuropsychiatric Disorders in Childhood. Am J Psychiatry 167: 1357-1363. doi:10.1176/appi. ajp.2010.10020223.

4. Ronald A, Hoekstra RA (2011) Autism spectrum disorders and autistic traits: A decade of new twin studies. Am J Med Genet B Neuropsychiatr Genet 156B: 255-274. doi:10.1002/ajmg.b.31159.

5. International Molecular Genetic Study of Autism Consortium (IMGSAC) (1998) A Full Genome Screen for Autism with Evidence for Linkage to a Region on Chromosome 7q. Hum Mol Genet 7: 571-578. doi:10.1093/hmg/7.3.571.

6. International Molecular Genetic Study of Autism Consortium (IMGSAC) (2001) A Genomewide Screen for Autism: Strong Evidence for Linkage to Chromosomes 2q, 7q, and 16p. Am J Hum Genet 69: 570-581. doi:10.1086/ 323264 .

7. Buxbaum JD, Silverman J, Keddache M, Smith GJ, Hollander E, et al. (2003) Linkage analysis for autism in a subset families with obsessive-compulsive behaviors: Evidence for an autism susceptibility gene on chromosome 1 and further support for susceptibility genes on chromosome 6 and 19. Mol Psychiatry 9: 144-150. doi:10.1038/sj.mp.4001465.

8. Martin CL, Ledbetter DH (2007) Autism and cytogenetic abnormalities: solving autism one chromosome at a time. Curr Psychiatry Rep 9: 141-147. coordinates and assay names for all TaqMan assays used for CNV confirmation. All coordinates are shown using hgl9 coordinates. Table S2. GNVs identified in Utah ASD families. The chromosomal locations and copy number status of all CNVs identified in Utah ASD families are shown. If $\mathrm{CNV}$ s had been observed in previous studies, the references are given below the table. Table S3. Literature GNVs. Chromosomal coordinates (hg19), source, and probe coverage on the custom Illumina array for each literature CNV characterized in this study. Table S4. GNVs identified using probes for sequence variants identified in Utah ASD families. Chromosome coordinates, TaqMan validation status, and copy number status for all CNVs identified using probes to sequence variants identified in Utah ASD families are shown. For one GNV the single TaqMan assay that was used failed PCR quality control.

(XLSX)

File S2 Supplemental methods and results. Supplemental methods. Details regarding sources of DNA samples used, methods for array processing, and sample quality control are described. Supplemental results. Analysis of population stratification using principal component analysis. The only samples used in CNV analyses were those demonstrated to be within the Caucasian group. His analysis included all cases and controls genotyped in this study.

(DOCX)

\section{Acknowledgments}

The authors gratefully acknowledge the resources provided by the Autism Genetic Resource Exchange (AGRE) Consortium and the participating AGRE families. Thanks to Frederick G. Otieno for his technical assistance and to Rena Vanzo for critical reading of the manuscript.

\section{Author Contributions}

Conceived and designed the experiments: NM DH CHH GBC CGL ML HH. Performed the experiments: CK EF KT RPdS JS LB BO TV. Analyzed the data: NM DH CHH GBC KH TL CGL ML HH. Contributed reagents/materials/analysis tools: DH GBC CGL HH. Wrote the paper: NM CHH ML.
9. Levy D, Ronemus M, Yamrom B, Lee Y, Leotta A, et al. (2011) Rare De Novo and Transmitted Copy-Number Variation in Autistic Spectrum Disorders. Neuron 70: 886-897. doi:10.1016/j.neuron.2011.05.015.

10. Betancur C (2011) Etiological heterogeneity in autism spectrum disorders: More than 100 genetic and genomic disorders and still counting. Brain Res 1380: 42 77. doi:10.1016/j.brainres.2010.11.078.

11. Sanders SJ, Murtha MT, Gupta AR, Murdoch JD, Raubeson MJ, et al. (2012) De novo mutations revealed by whole-exome sequencing are strongly associated with autism. Nature 485(7397):237-241. doi:10.1038/nature10945

12. Iossifov I, Ronemus M, Levy D, Wang Z, Hakker I, et al. (2012) De Novo Gene Disruptions in Children on the Autistic Spectrum. Neuron 74: 285-299. doi:10.1016/j.neuron.2012.04.009.

13. Girirajan S, Brkanac Z, Coe BP, Baker C, Vives L, et al. (2011) Relative burden of large CNVs on a range of neurodevelopmental phenotypes. PLoS Genet 7: e1002334. doi:10.1371/journal.pgen.1002334.

14. Sebat J, Lakshmi B, Malhotra D, Troge J, Lese-Martin C, et al. (2007) Strong Association of De Novo Copy Number Mutations with Autism. Science 316: 445-449. doi:10.1126/science.1138659.

15. Marshall GR, Noor A, Vincent JB, Lionel AC, Feuk L, et al. (2008) Structural Variation of Chromosomes in Autism Spectrum Disorder. Am J Hum Genet 82: 477-488. doi:10.1016/j.ajhg.2007.12.009.

16. Christian SL, Brune CW, Sudi J, Kumar RA, Liu S, et al. (2008) Novel Submicroscopic Chromosomal Abnormalities Detected in Autism Spectrum Disorder. Biol Psychiatry 63: 1111-1117. doi:10.1016/j.biopsych.2008.01.009.

17. Glessner JT, Wang K, Cai G, Korvatska O, Kim CE, et al. (2009) Autism genome-wide copy number variation reveals ubiquitin and neuronal genes. Nature 459: 569-573. doi:10.1038/nature07953.

18. Bucan M, Abrahams BS, Wang K, Glessner JT, Herman EI, et al. (2009) Genome-Wide Analyses of Exonic Copy Number Variants in a Family-Based 
Study Point to Novel Autism Susceptibility Genes. PLoS Genet 5: e1000536. doi:10.1371/journal.pgen.1000536.

19. Pinto D, Pagnamenta AT, Klei L, Anney R, Merico D, et al. (2010) Functional impact of global rare copy number variation in autism spectrum disorders. Nature 466: 368-372. doi:10.1038/nature09146.

20. Szatmari P, Paterson AD, Zwaigenbaum L, Roberts W, Brian J (2007) Mapping autism risk loci using genetic linkage and chromosomal rearrangements. Nat Genet 39: 319-328. doi:10.1038/ng1985.

21. Weiss LA, Shen Y, Korn JM, Arking DE, Miller DT, et al. (2008) Association between Microdeletion and Microduplication at $16 \mathrm{p} 11.2$ and Autism. N Engl J Med 358: 667-675. doi:10.1056/NEJMoa075974.

22. Morrow EM, Yoo S-Y, Flavell SW, Kim T-K, Lin Y, et al. (2008) Identifying Autism Loci and Genes by Tracing Recent Shared Ancestry. Science 321: 218 223. doi:10.1126/science. 1157657.

23. Jacquemont M-L, Sanlaville D, Redon R, Raoul O, Cormier-Daire V, et al. (2006) Array-based comparative genomic hybridisation identifies high frequency of cryptic chromosomal rearrangements in patients with syndromic autism spectrum disorders. J Med Genet 43: 843-849. doi:10.1136/jmg.2006.043166.

24. Shinawi M, Liu P, Kang S-HL, Shen J, Belmont JW, et al. (2010) Recurrent reciprocal 16p11.2 rearrangements associated with global developmental delay, behavioural problems, dysmorphism, epilepsy, and abnormal head size. J Med Genet 47: 332-341. doi:10.1136/jmg.2009.073015.

25. Shen Y, Dies KA, Holm IA, Bridgemohan C, Sobeih MM, et al. (2010) Clinical Genetic Testing for Patients With Autism Spectrum Disorders. Pediatrics 125: e727-e735. doi: 10.1542/peds.2009-1684

26. Fernandez BA, Roberts W, Chung B, Weksberg R, Meyn S, et al. (2010) Phenotypic spectrum associated with de novo and inherited deletions and duplications at 16 p11.2 in individuals ascertained for diagnosis of autism spectrum disorder. J Med Genet 47: 195-203. doi:10.1136/jmg.2009.069369.

27. Lionel AC, Crosbie J, Barbosa N, Goodale T, Thiruvahindrapuram B, et al. (2011) Rare copy number variation discovery and cross-disorder comparisons identify risk genes for ADHD. Sci Transl Med 3: 95ra75. doi:10.1126/ scitranslmed.3002464.

28. Sahoo T, Theisen A, Rosenfeld JA, Lamb AN, Ravnan JB, et al. (2011) Copy number variants of schizophrenia susceptibility loci are associated with a spectrum of speech and developmental delays and behavior problems. Genet Med 13: 868-880. doi:10.1097/GIM.0b013e3182217a06.

29. Kirov G, Pocklington AJ, Holmans P, Ivanov D, Ikeda M, et al. (2012) De novo GNV analysis implicates specific abnormalities of postsynaptic signalling complexes in the pathogenesis of schizophrenia. Mol Psychiatry 17: 142-153. doi: $10.1038 / \mathrm{mp} .2011 .154$.

30. Manning M, Hudgins L (2010) Array-based technology and recommendations for utilization in medical genetics practice for detection of chromosomal abnormalities. Genet Med 12: 742-745. doi: 10.1097/GIM.0b013e3181f8baad.

31. Miller DT, Adam MP, Aradhya S, Biesecker LG, Brothman AR, et al. (2010) Consensus Statement: Chromosomal Microarray Is a First-Tier Clinical Diagnostic Test for Individuals with Developmental Disabilities or Congenital Anomalies. Am J Hum Genet 86: 749-764. doi: 10.1016/j.ajhg.2010.04.006.

32. Glessner JT, Wang K, Cai G, Korvatska O, Kim CE, et al. (2009) Autism genome-wide copy number variation reveals ubiquitin and neuronal genes. Nature 459: 569-573. doi:10.1038/nature07953.

33. Qiao Y, Riendeau N, Koochek M, Liu X, Harvard C, et al. (2009) Phenomic determinants of genomic variation in autism spectrum disorders. J Med Genet 46: 680-688. doi:10.1136/jmg.2009.066795.

34. Wang K, Li M, Hadley D, Liu R, Glessner J, et al. (2007) PennCNV: An integrated hidden Markov model designed for high-resolution copy number variation detection in whole-genome SNP genotyping data. Genome Res 17: 1665-1674. doi:10.1101/gr.6861907.

35. Kent WJ, Sugnet CW, Furey TS, Roskin KM, Pringle TH, et al. (2002) The human genome browser at UCSC. Genome Res 12: 996-1006. doi:10.1101/ gr.229102.

36. Feng J, Schroer R, Yan J, Song W, Yang C, et al. (2006) High frequency of neurexin $1 \beta$ signal peptide structural variants in patients with autism. Neurosci Lett 409: 10-13. doi:10.1016/j.neulet.2006.08.017.

37. Kim H-G, Kishikawa S, Higgins AW, Seong I-S, Donovan DJ, et al. (2008) Disruption of Neurexin 1 Associated with Autism Spectrum Disorder. Am J Hum Genet 82: 199-207.

38. Ching MSL, Shen Y, Tan W-H, Jeste SS, Morrow EM, et al. (2010) Deletions of NRXN1 (neurexin-1) predispose to a wide spectrum of developmental disorders. Am J Med Genet B Neuropsychiatr Genet 153B: 937-947. doi:10.1002/ ajmg.b.31063.

39. Schaaf CP, Boone PM, Sampath S, Williams C, Bader PI, et al. (2012) Phenotypic spectrum and genotype-phenotype correlations of NRXN1 exon deletions. Eur J Hum Genet. Available:http://dx.doi.org/10.1038/ejhg.2012. 95.

40. Camacho-Garcia RJ, Planelles MI, Margalef M, Pecero ML, Martínez-Leal R, et al. (2012) Mutations affecting synaptic levels of neurexin-1 $\beta$ in autism and mental retardation. Neurobiol Dis 47: 135-143. doi:10.1016/j.nbd.2012.03.031.

41. Wu Y-W, Prakash K, Rong T-Y, Li H-H, Xiao O, et al. (2011) Lingo2 variants associated with essential tremor and Parkinson's disease. Hum Genet 129: 611615. doi:10.1007/s00439-011-0955-3.

42. Yamamoto Y, Mochida S, Miyazaki N, Kawai K, Fujikura K, et al. (2010) Tomosyn Inhibits Synaptotagmin-1-mediated Step of Ca2+-dependent Neuro- transmitter Release through Its N-terminal WD40 Repeats. J Biol Chem 285: 40943-40955. doi:10.1074/jbc.M1 10.156893.

43. Williams AL, Bielopolski N, Meroz D, Lam AD, Passmore DR, et al. (2011) Structural and Functional Analysis of Tomosyn Identifies Domains Important in Exocytotic Regulation. J Biol Chem 286: 14542-14553. doi:10.1074/ jbc.M1 10.215624

44. Hedges D, Hamilton-Nelson K, Sacharow S, Nations L, Beecham G, et al. (2012) Evidence of novel fine-scale structural variation at autism spectrum disorder candidate loci. Mol Autism 3:2. doi: 10.1186/2040-2392-3-2.

45. Nunn G, Mao H, Chidiac P, Albert PR (2006) RGS17/RGSZ2 and the RZ/A family of regulators of G-protein signaling. Semin Cell Dev Biol 17: 390-399. doi:10.1016/j.semcdb.2006.04.001.

46. Shema E, Kim J, Roeder RG, Oren M (2011) RNF20 inhibits TFIIS-facilitated transcriptional elongation to suppress pro-oncogenic gene expression. Mol Cell 42: 477-488. doi:10.1016/j.molcel.2011.03.011.

47. Carrié A, Jun L, Bienvenu T, Vinet MC, McDonell N, et al. (1999) A new member of the IL-1 receptor family highly expressed in hippocampus and involved in X-linked mental retardation. Nat Genet 23: 25-31. doi:10.1038/ 12623.

48. Gambino F, Pavlowsky A, Béglé A, Dupont J-L, Bahi N, et al. (2007) IL1receptor accessory protein-like 1 (IL1RAPL1), a protein involved in cognitive functions, regulates N-type Ca2+-channel and neurite elongation. Proc Natl Acad Sci USA 104: 9063-9068. doi:10.1073/pnas.0701133104.

49. Biswas AK, Johnson DG (2012) Transcriptional and nontranscriptional functions of E2F1 in response to DNA damage. Cancer Res 72: 13-17. doi:10.1158/0008-5472.CAN-11-2196.

50. Sumioka A, Imoto S, Martins RN, Kirino Y, Suzuki T (2003) XB51 isoforms mediate Alzheimer's beta-amyloid peptide production by X11L (X11-like protein)-dependent and -independent mechanisms. Biochem J 374: 261-268. doi: 10.1042/BJ20030489.

51. Stone TW, Forrest CM, Darlington LG (2012) Kynurenine pathway inhibition as a therapeutic strategy for neuroprotection. FEBS J 279: 1386-1397. doi: $10.1111 / \mathrm{j} .1742-4658.2012 .08487 . x$.

52. Sun J, Jayathilake K, Zhao Z, Meltzer HY (2012) Investigating association of four gene regions (GABRB3, MAOB, PAH, and SLC6A4) with five symptoms in schizophrenia. Psychiatry Res. Available: http://www.sciencedirect.com/ science/article/pii/S0165178111008195.

53. Yalçın Ö (2012) Genes and molecular mechanisms involved in the epileptogenesis of idiopathic absence epilepsies. Seizure 21: 79-86. doi: 10.1016/ j.seizure.2011.12.002.

54. Kirov G, Rujescu D, Ingason A, Collier DA, O'Donovan MC, et al, (2009) Neurexin 1 (NRXN1) Deletions in Schizophrenia. Schizophr Bull 35: 851-854. doi:10.1093/schbul/sbp079.

55. Harrison V, Connell L, Hayesmoore J, McParland J, Pike MG, et al. (2011) Compound heterozygous deletion of NRXN1 causing severe developmental delay with early onset epilepsy in two sisters. Am J Med Genet A. 155A: 28262831. doi:10.1002/ajmg.a.34255.

56. Kalia LV, Kalia SK, Chau H, Lozano AM, Hyman BT, et al. (2011) Ubiquitinylation of $\alpha$-Synuclein by Carboxyl Terminus Hsp70-Interacting Protein (CHIP) Is Regulated by Bcl-2-Associated Athanogene 5 (BAG5). PLoS ONE 6: e14695. doi:10.1371/journal.pone.0014695.

57. Swaminathan S, Kim S, Shen L, Risacher SL, Foroud T (2011) Genomic Copy Number Analysis in Alzheimer's Disease and Mild Cognitive Impairment: An ADNI Study. Int J Alzheimers Dis 2011: 10. doi:10.4061/2011/729478.

58. Håvik B, Le Hellard S, Rietschel M, Lybæk H, Djurovic S, et al. (2011) The Complement Control-Related Genes CSMD1 and CSMD2 Associate to Schizophrenia. Biol Psychiatry 70: 35-42. doi: 10.1016/j.biopsych.2011.01.030.

59. Vilariño-Güell C, Wider C, Ross O, Jasinska-Myga B, Kachergus J, et al. (2010) LINGO1 and LINGO2 variants are associated with essential tremor and Parkinson disease. Neurogenetics 11: 401-408. doi:10.1007/s10048-010-0241-x.

60. Punia S, Das M, Behari M, Mishra BK, Sahani AK, et al. (2010) Role of polymorphisms in dopamine synthesis and metabolism genes and association of DBH haplotypes with Parkinson's disease among North Indians. Pharmacogenet Genomics 20:435-441. doi:10.1097/FPC.0b013e32833ad3bb.

61. Kao W-T, Wang Y, Kleinman JE, Lipska BK, Hyde TM, et al. (2010) Common genetic variation in Neuregulin 3 (NRG3) influences risk for schizophrenia and impacts NRG3 expression in human brain. Proc Natl Acad Sci U S A 107: 15619-15624. doi:10.1073/pnas.1005410107.

62. Grant SG (2012) Synaptopathies: diseases of the synaptome. Curr Opin Neurobiol 22:522-529. Available: http://www.sciencedirect.com/science/ article/pii/S0959438812000244.

63. Michel M, Schmidt MJ, Mirnics K (2012) Immune system gene dysregulation in autism \& schizophrenia. Dev Neurobiol. Available: http://www.ncbi.nlm.nih. gov/pubmed/22753382. Accessed 20 July 2012.

64. Davis LK, Meyer KJ, Rudd DS, Librant AL, Epping EA, et al. (2009) Novel copy number variants in children with autism and additional developmental anomalies. J Neurodev Disord 1: 292-301. doi:10.1007/s11689-009-9013-z.

65. Kang J-Q Barnes G (2012) A Common Susceptibility Factor of Both Autism and Epilepsy: Functional Deficiency of GABA $\mathrm{A}$ Receptors. J Autism Dev Disord 42: 1-12. doi:10.1007/s10803-012-1543-7.

66. Hogart A, Nagarajan RP, Patzel KA, Yasui DH, Lasalle JM (2007) 15q11-13 GABAA receptor genes are normally biallelically expressed in brain yet are subject to epigenetic dysregulation in autism-spectrum disorders. Hum $\mathrm{Mol}$ Genet 16: 691-703. doi:10.1093/hmg/ddm014. 
67. Cook EH Jr, Lindgren V, Leventhal BL, Courchesne R, Lincoln A, et al. (1997) Autism or atypical autism in maternally but not paternally derived proximal $15 \mathrm{q}$ duplication. Am J Hum Genet 60: 928-934.

68. Xu L, Li Y, Zhang X, Sun H, Sun D, et al. (2011) Deletion of LCE3C and LCE3B genes is associated with psoriasis in a northern Chinese population. Br J Dermatol 165: 882-887. doi:10.1111/j.1365-2133.2011.10485.x.

69. Bergboer JGM, Zeeuwen PLJM, Schalkwijk J (2012) Genetics of Psoriasis: Evidence for Epistatic Interaction between Skin Barrier Abnormalities and Immune Deviation. The J Invest Dermatol. Available: http://www.ncbi.nlm. nih.gov/pubmed/22622420. Accessed 20 July 2012

70. Prescott SM, Lalouel JM, Leppert M (2008) From Linkage Maps to Quantitative Trait Loci: The History and Science of the Utah Genetic Reference Project.
Annu Rev Genom Human Genet 9: 347-358. doi:10.1146/annurev.genom. 9.081307.164441.

71. Price AL, Patterson NJ, Plenge RM, Weinblatt ME, Shadick NA, et al. (2006) Principal components analysis corrects for stratification in genome-wide association studies. Nat Genet 38: 904-909. doi:10.1038/ng1847.

72. Huang DW, Sherman BT, Lempicki RA (2008) Systematic and integrative analysis of large gene lists using DAVID bioinformatics resources. Nat Protocols 4: 44-57. doi:10.1038/nprot.2008.211.

73. Huang DW, Sherman BT, Lempicki RA (2009) Bioinformatics enrichment tools: paths toward the comprehensive functional analysis of large gene lists. Nucleic Acids Res 37: 1-13. doi:10.1093/nar/gkn923. 